\section{Development of a Branching Index for Evaluation of Peach Seedlings Using Interspecific Hybrids}

\author{
Omar Carrillo-Mendoza, Wayne B. Sherman, and José X. Chaparro ${ }^{1}$ \\ Horticultural Sciences Department, University of Florida, 1117 Fifield Hall, \\ P.O. Box 110690, Gainesville, FL 32611-0690
}

Additional index words. Prunus persica, P. kansuensis, $P$. dulcis, plant architecture, peach breeding

\begin{abstract}
Trees without excessive branching are desirable for the reduction of pruning costs. Genetic diversity for less twiggy genotypes exists in peach and a branching index was developed for evaluation and selection of genotypes with reduced branching. The index is based on the number of total first-order branches and the number of second-order, thirdorder, and fourth-order branches measured on three randomly selected first-order branches. Index values were highly correlated $\left(r^{2} \approx 0.7\right)$ with the total number of branches over two growing seasons and served as a good predictor of branching patterns observed in the third growing season. Thus, the developed branching index is a useful tool in peach breeding, allowing for the early selection of trees with more desirable tree architecture.
\end{abstract}

Most temperate fruit tree breeding programs pay major attention to fruit quality, chilling requirement, crop load, and tolerance to disease. In contrast, limited effort has been devoted to tree architecture and tree branching patterns (Berthelemy and Caraglio, 2007). As labor and pruning costs of fruit trees have increased, size control and tree architecture in fruit trees have gained importance. Tools for the evaluation and early selection of architectural traits expressed late in development would represent a major advancement for fruit tree breeders (Laurens et al., 2000). Factors such as tree vigor and sylleptic (immediate) and proleptic (delayed) branching have major effects on the presence of a large number of thin branches or "twigginess" of stone fruit trees.

Various types of plant growth models that integrate plant topology and plant geometry to study plant architecture are available (Fourcaud et al., 2008). Another means to portray plant architecture is the development of indices (Godin et al., 1999). An index based on the plastochron development of Glecoma hederacea $L$. was used to analyze stolon growth and branching (Birch and Hutchings, 1992). An index based on length and density or number of first-order and second-order roots was used to describe the degree of branching in maize roots (Morita et al., 1992). Analysis of lateral branching has been used to study architectural traits. In apple, lateral branching has high heritability and is correlated with topological traits (Segura et al., 2006).

Tworkoski and Scorza (2001) indicate that although there are numerous growth forms in peach, little effort has been made

Received for publication 15 July 2009. Accepted for publication 17 Aug. 2009.

${ }^{1}$ To whom reprint requests should be addressed; e-mail jchaparro@ifas.ufl.edu. to describe and control tree architecture. They stated that compact peach trees have aim of this research was to develop a simple and reliable branching index that could be used to evaluate the architecture of peach seedlings, thus facilitating the early selection of individuals with desirable tree architecture. The developed index uses first-order branch data and higher-order branch data from three first-order branches as the basis to characterize seedling trees.

\section{Materials and Methods}

A branching index (BI) equation categonontwiggy phenotypes while at same time maintaining quantitative differences within these categories was desired. The BI was specifically designed for the evaluation of peach and interspecific Prunus seedlings in the highdensity fruiting nursery management of the University of Florida stone fruit breeding program. The BI value is the multiplication of partial index values for each branching order existent within the plant: first-order branches that arise from the main axes, second-order branches arising from first-order branches, and so on. The BI formula is:

$$
\mathrm{BI}=\prod_{i=1}^{k} 2^{\left(x_{i}+\frac{n_{i}}{100}\right)}
$$

where $x=\operatorname{absence}(x=0)$ or presence $(x=1)$ of first-, second-, third-, or subsequent order branches; $n=$ number of branches within a branching order; and $k=$ the maximum order of branching.

For illustration purposes, we mention the next cases: Plants having no branches have BI values of 1 . Plants having only first-order branches; first- and second-order branches; and first-, second-, and third-order branches would have values of $2<\mathrm{BI}<4,4<\mathrm{BI}<8$, increased branching in roots and limbs. The rizing plants into twiggy, intermediate, and and $8<\mathrm{BI}<16$, respectively. For example, a plant with a single stem (i.e., no branches) would result in the equation $2^{[0+(0 / 100)]}$ and yield a value of 1 . For a plant with three primary branches and no higher-order branches, the equation $2^{[1+(3 / 100)]}$ would yield a value 2.04. The branching index for a plant with three primary and two secondary branches would be calculated as $2^{[1+(3 / 100)]} \times 2^{[1+(2 / 100)]}$ and yield a value of 4.14 . Although permutations of this equation were performed using weights for the presence of branches $(1.5,2.0$, 2.5 , and 3 ) and weights for branch numbers (ranging from 100 to 1000), the first equation was better able to separate the plants into different clusters representing different branching orders showing qualitative contrasts. For this reason, the first equation was chosen for the index.

The germplasm used to generate the populations for validating the BI equation represents three sexually compatible Prunus species with differing growth habits: Kansu peach (P. kansuensis Rehder), almond $[P$. dulcis (Mill.) D.A. Webb], and peach $[P$. persica (L.) Batsch]. Kansu peach, a wild peach relative, has a dense canopy with profuse branching under the growing conditions of the southeastern United States. In contrast, almond has reduced branching, an open tree canopy, and can produce short branches or spurs. Commercial peach germplasm typically has a branching architecture that is intermediate to the two described previously but includes both twiggy and nontwiggy phenotypes.

F1 hybrid populations of peach $\times P$. kansuensis and peach $\times P$. dulcis populations were generated and planted in Gainesville, FL, $0.5 \mathrm{~m}$ apart in a single row. The plants were lightly pruned the first growing season by cutting off suckers from the basal part, whereas the main axis was maintained throughout the entire experiment. Data were collected on the total number of branches represented by total number of tips; number of first-order branches; and the number of second-, third-, and fourth-order branches from three randomly selected firstorder branches on 2- and 3-year-old seedlings of FL97-47C peach $\times$ 'Tardy Nonpareil' (TNP) almond, 'Okinawa' (Oki) peach $\times P$. kansuensis ' $A$ ', 'Flordaguard' (FG) peach $\times P$. kansuensis ' $\mathrm{A}$ ', and $\mathrm{FG}$ peach $\times$ TNP almond. These sample branches were located at the basal, intermediate, and upper third of the tree in years 2007 and 2008. Trees were between 1.5 and $2 \mathrm{~m}$ tall when 2 years old and ranged from 4 to $5 \mathrm{~m}$ tall when 3 years old. The first-, second-, third-, and fourth-order branching data were used to calculate an index value to estimate and predict the number of branches.

A comparison of the accuracy of BI based on one branch per tree (randomly selected in the basal, intermediate, or upper third of each tree) versus the mean of three branches per tree was performed to determine if data from only one first-order branch were sufficient to obtain a good correlation between the BI and the total number of branches represented by total number of tips. The statistical analysis consisted of analysis of variance, Tukey mean test between the different families evaluated, 
and the clusters formed by trees that reached the same branching order (first, second, third, and fourth order) for both years. The statistical analysis was performed using SAS, Version 9.1 (SAS Institute Inc., Cary, NC).

\section{Results and Discussion}

Results showed that 'FL97-47C' peach $x$ TNP almond and FG peach $\times$ TNP hybrids had the fewest mean total number of branches and lowest branching index in both years (Table 1; Figs. 1A-B). Peach $\times$ TNP hybrids also had fewer first- and second-order branches in 2007 and fewer first-, second-, and thirdorder branches in 2008. Therefore, branch pro-

Table 1. Mean total branch number per tree and branching index values in peach $\times$ almond and peach $\times P$. kansuensis F1 hybrid populations in years 2007 and 2008.

\begin{tabular}{lccccc}
\hline & \multicolumn{2}{c}{2007} & & 2008 \\
\cline { 2 - 3 } \cline { 5 - 6 } Family & Branches (no.) & Branching index value & & Branches (no.) & Branching index value \\
\hline Oki $\times$ Pkan & $97.20 \mathrm{a}^{\mathrm{y}}$ & $10.34 \mathrm{a}$ & & $245.16 \mathrm{a}$ & $19.56 \mathrm{a}$ \\
FG $\times$ Pkan & $63.80 \mathrm{~b}$ & $8.32 \mathrm{~b}$ & & $235.33 \mathrm{a}$ & $13.20 \mathrm{a}$ \\
FL97-47C $\times$ TNP & $15.63 \mathrm{c}$ & $2.48 \mathrm{c}$ & & $45.00 \mathrm{~b}$ & $5.06 \mathrm{~b}$ \\
FG $\times$ TNP & $5.80 \mathrm{c}$ & $2.44 \mathrm{c}$ & & $26.75 \mathrm{~b}$ & $5.05 \mathrm{~b}$
\end{tabular}

${ }^{2} \mathrm{TNP}=$ 'Tardy Nonpareil'; FG = Flordaguard; Pkan $=$ P. kansuensis; Oki $=$ 'Okinawa'.

${ }^{y}$ Means followed by different letters are significantly different (Tukey, $P \leq 0.05$ ).

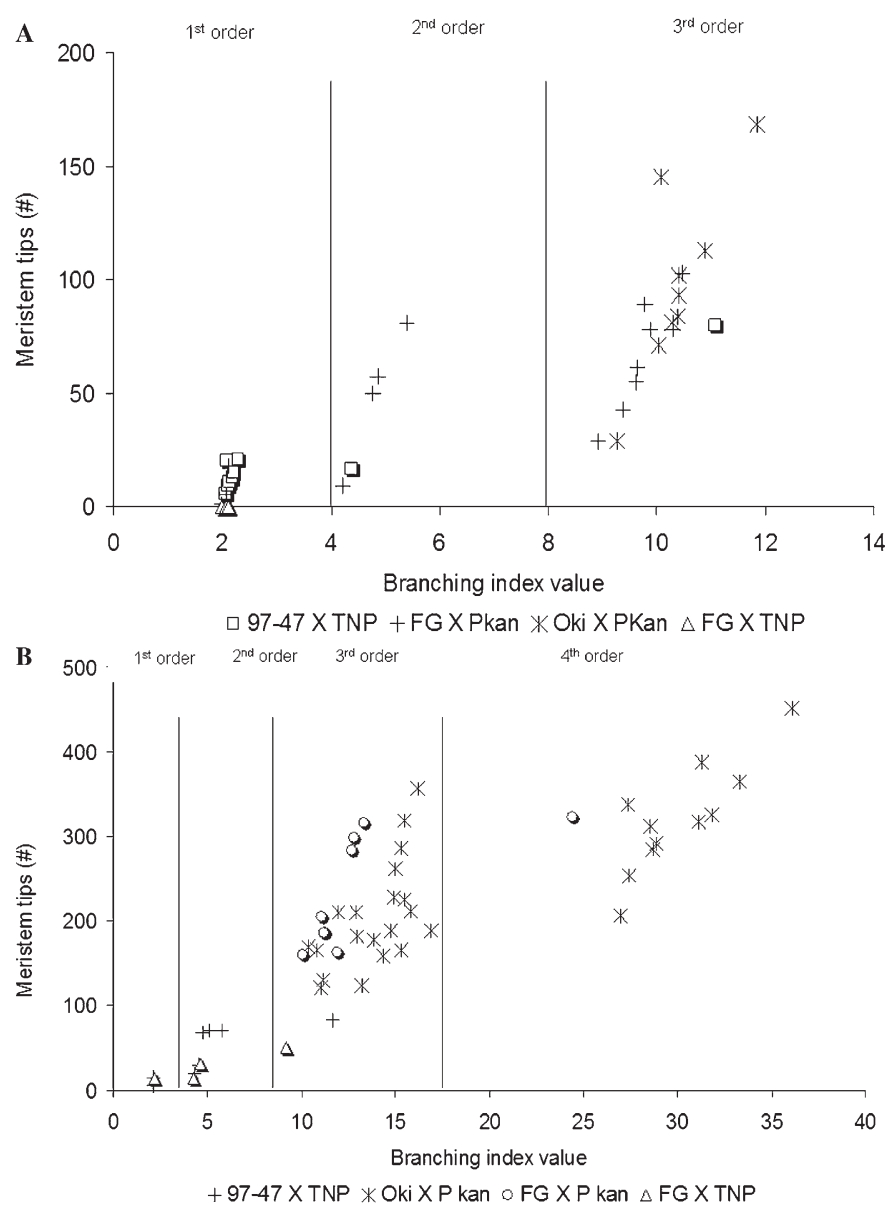

Fig. 1. Branching index values generated for year 2007 (A) and 2008 (B) plotted against number of meristem tips in FL97-47C peach $\times$ 'Tardy Nonpareil' (TNP) almond, 'Okinawa' (Oki) peach $\times$ P. kansuensis 'A' (Pkan), 'Flordaguard' (FG) peach $\times$ P. kansuensis 'A', and 'Flordaguard' peach $\times$ 'Tardy Nonpareil' almond progeny. Index values were calculated using the total number of first-order branches per tree and the mean of three randomly selected first-order branches in the case of second- and third-order branches. Vertical lines show borders between trees having different branching order. first-order branches in both 2007 and 2008 and the most second- and third-order branches in 2008 , yet the differences were significant only for 2007 first-order branch data.

The largest number of total branches and $\mathrm{BI}$ was observed in peach $\times P$. kansuensis ' $\mathrm{A}$ ' hybrids (Table 1; Fig. 3). Increased branching was also observed for higher-order branching in $P$. kansuensis hybrids (Table 2 ). The third-order cluster in 2007 and the fourth-order cluster in 2008 were composed entirely of peach $\times P$. kansuensis hybrids (Fig. 1). In addition all but three data points in the third-order cluster for 2008 were peach $\times$ $P$. kansuensis hybrids. Oki peach $\times P$. kansuensis $\mathrm{F} 1$ hybrids had the greatest total branches in both 2007 and 2008. However, Oki $\times P$. kansuensis was significantly different from $\mathrm{FG} \times P$. kansuensis only in 2007. Comparison of the $\mathrm{FG} \times \mathrm{TNP}$ and $\mathrm{FG} \times P$. kansuensis $\mathrm{F} 1$ families shows that the $\mathrm{FG} \times P$. kansuensis F1 family had greater than fourfold the mean total number of branches in both 2007 and 2008 and approximately fivefold more first-order and twofold more secondorder branches than the FG $\times$ TNP family.

FG can be compared with FL97-47c because both were crossed to TNP. FG can also be compared with Oki because both were crossed to $P$. kansuensis. In these comparisons, FG consistently produced progeny with the smallest mean total number of branches and lowest $\mathrm{BI}$ value when compared with FL97-47C and Oki for both the TNP and $P$. kansuensis F1 hybrids. FG is characterized by long, whippy branches and reduced branching (Sherman et al., 1991), whereas Oki and

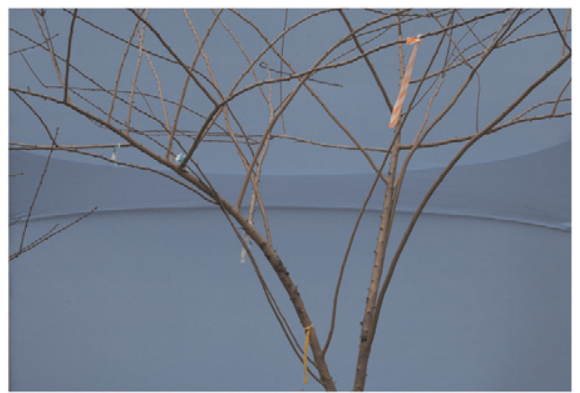

Fig. 2. Reduced branching typical of a 3-year-old 'Flordaguard' peach $\times$ 'Tardy nonpareil' almond hybrid in winter of 2008

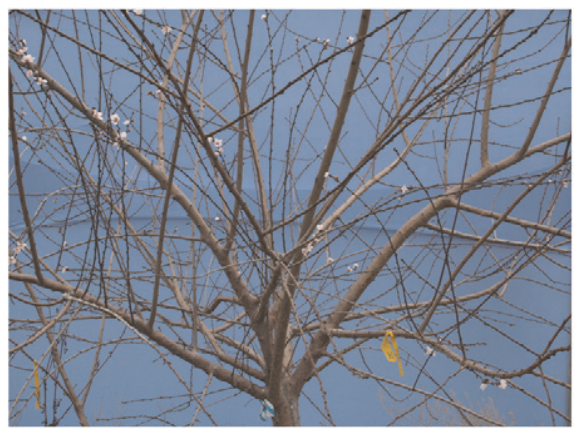

Fig. 3. Profuse branching typical of a 3-year-old 'Flordaguard' peach $\times P$. kansuensis hybrid in winter of 2008. 
FL97-42C produce shorter and twiggier branches. The variation in branching observed in the hybrid populations indicates that there is a large genetic component to branching propensity in peach and related species. Genard et al. (1994) reported that branching in peach depends on physiological factors, although induction levels varied from one cultivar to another. Similarly, the number of lateral shoots in apricot was significantly affected by genotype in cumulative data for the first 2 years, whereas 3 years were required to differentiate between tree architectures (Legave et al., 2006). They proposed that it is necessary to observe the expression of genetic contrasts in growth and branching on appropriate parts of the limbs and use the early expression of these traits to allow early selection of preferred tree architecture (Legave et al., 2006).

The values generated by the BI equation plotted against the total number of meristem tips grouped the progeny into clusters of seedlings that were differentiated by the presence or absence of first-order, second-order, thirdorder, and fourth-order branches (Fig. 1A-B). The first-order cluster in 2007 and the firstand second-order clusters in 2008 consisted entirely of peach $\times$ TNP hybrids. The thirdorder branching cluster in 2007 and the fourthorder branching cluster in 2008 consisted of peach $\times P$. kansuensis hybrids. It was only in the second-order branching cluster for 2007 and the third-order branching cluster for 2008 that contained both peach $\times$ TNP almond and peach $\times P$. kansuensis hybrids. Although the distributions of the observed total number of branches overlapped between clusters, the mean total number of branches was different among the first-, second-, and third-order groups in 2007 and among the second-, third-, and fourth-order groups in 2008 (Table $3)$. The mean number of branches in the firstorder and second-order branching groups was not significantly different in 2008. This lack of significance in 2008 between the first-order and second-order groups may have resulted because only three trees had not undergone second-order branching in the sampled limbs. The first-order branching cluster consisted of trees with index values between roughly 2 and 4 , second-order branching cluster between 4 and 8 , third-order branching cluster between 8 and 16, and fourth-order branching cluster greater than 16 (Figs. 4 and 5).

The regression lines for 2007 (Fig. 4A) and 2008 (Fig. 5A) demonstrate the general trend of the groups generated by the index. The regression between the index values and the total number of apical meristems were 0.72 and 0.78 for 2007 and 2008, respectively. However, these regression lines do not show the within-cluster progression of branch number as the index values increase. In 2007, trees that developed first-, second-, and third-order branching were tightly grouped. It was possible to fit regression lines with high $r^{2}$ values, indicating that the index values were good predictors of branching intensity within each cluster (Fig. 4B). The number of plants with third-order branches increased and plants with fourth-order branches appeared in 2008 (Fig.
Table 2. Mean number of first-order branches and the mean number of second-, third-, and fourth-order branches in three first-order branches sampled per tree of peach $\times$ almond and peach $\times$ P. kansuensis $\mathrm{F} 1$ hybrids.

\begin{tabular}{|c|c|c|c|c|c|c|}
\hline Family $^{z}$ & $\mathrm{Yr}$ & $\begin{array}{c}\text { Progeny } \\
\text { evaluated (no.) }\end{array}$ & $\begin{array}{c}\text { First } \\
\text { order (no.) }\end{array}$ & $\begin{array}{c}\text { Second } \\
\text { order (no.) }\end{array}$ & $\begin{array}{c}\text { Third } \\
\text { order (no.) }\end{array}$ & $\begin{array}{c}\text { Fourth } \\
\text { order (no.) }\end{array}$ \\
\hline$\overline{\mathrm{Oki}} \times$ Pkan & 2007 & 10 & $26.40 \mathrm{a}^{\mathrm{y}}$ & $8.36 \mathrm{a}$ & $2.00 \mathrm{a}$ & 0.00 \\
\hline $\mathrm{FG} \times \mathrm{Pkan}$ & & 10 & $22.40 \mathrm{a}$ & $5.76 \mathrm{a}$ & $1.33 \mathrm{a}$ & 0.00 \\
\hline FL97-47C $\times$ TNP & & 8 & $11.37 \mathrm{~b}$ & $2.73 \mathrm{~b}$ & $0.00 \mathrm{a}$ & 0.00 \\
\hline $\mathrm{FG} \times \mathrm{TNP}$ & & 5 & $4.40 \mathrm{c}$ & $2.60 \mathrm{~b}$ & $0.00 \mathrm{a}$ & 0.00 \\
\hline Oki $\times$ Pkan & 2008 & 31 & $43.23 \mathrm{a}$ & $25.17 \mathrm{a}$ & $13.96 \mathrm{a}$ & $0.65 \mathrm{a}$ \\
\hline $\mathrm{FG} \times$ Pkan & & 8 & $32.22 \mathrm{~b}$ & $15.26 \mathrm{~b}$ & $12.41 \mathrm{a}$ & $0.11 \mathrm{a}$ \\
\hline FL97-47C $\times$ TNP & & 8 & $19.88 \mathrm{c}$ & $4.92 \mathrm{c}$ & $2.46 \mathrm{~b}$ & $0.00 \mathrm{a}$ \\
\hline $\mathrm{FG} \times \mathrm{TNP}$ & & 4 & $12.25 \mathrm{c}$ & $3.25 \mathrm{c}$ & $0.25 \mathrm{~b}$ & $0.00 \mathrm{a}$ \\
\hline
\end{tabular}

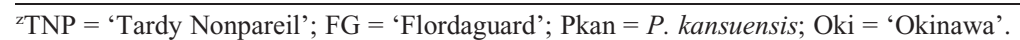

${ }^{\mathrm{y}}$ Means followed by different letters are significantly different (Tukey, $P \leq 0.05$ ).

Table 3. Mean total branch number per tree and branching index means for first-, second-, third-, and fourth-order branching clusters in peach $\times$ almond and peach $\times P$. kansuensis $\mathrm{F} 1$ hybrid populations in 2007 and 2008.

\begin{tabular}{|c|c|c|c|c|}
\hline \multirow[b]{2}{*}{$\begin{array}{l}\text { Branching } \\
\text { cluster }^{z}\end{array}$} & \multicolumn{2}{|c|}{2007} & \multicolumn{2}{|c|}{2008} \\
\hline & $\begin{array}{l}\text { Branches } \\
\text { (total no.) }\end{array}$ & $\begin{array}{l}\text { Branching } \\
\text { index value }\end{array}$ & $\begin{array}{l}\text { Branches } \\
\text { (total no.) }\end{array}$ & $\begin{array}{l}\text { Branching } \\
\text { index value }\end{array}$ \\
\hline First order & $11.33 \mathrm{c}^{\mathrm{y}}$ & $2.12 \mathrm{c}$ & $11.64 \mathrm{c}$ & $2.15 \mathrm{c}$ \\
\hline Second order & $42.80 \mathrm{~b}$ & $4.72 \mathrm{~b}$ & $43.00 \mathrm{c}$ & $4.70 \mathrm{c}$ \\
\hline Third order & $83.65 \mathrm{a}$ & $10.09 \mathrm{a}$ & $194.79 \mathrm{~b}$ & $12.85 \mathrm{~b}$ \\
\hline Fourth order & 0 & $\mathrm{ND}^{\mathrm{x}}$ & $314.01 \mathrm{a}$ & $27.78 \mathrm{a}$ \\
\hline
\end{tabular}

${ }^{\mathrm{z}}$ Cluster was assigned on the branching order reached by the tree.

${ }^{y}$ Means followed by different letters are significantly different (Tukey, $P \leq 0.05$ ).

${ }^{\mathrm{x}} \mathrm{ND}=$ no data, no trees reached fourth-order branching in 2007.
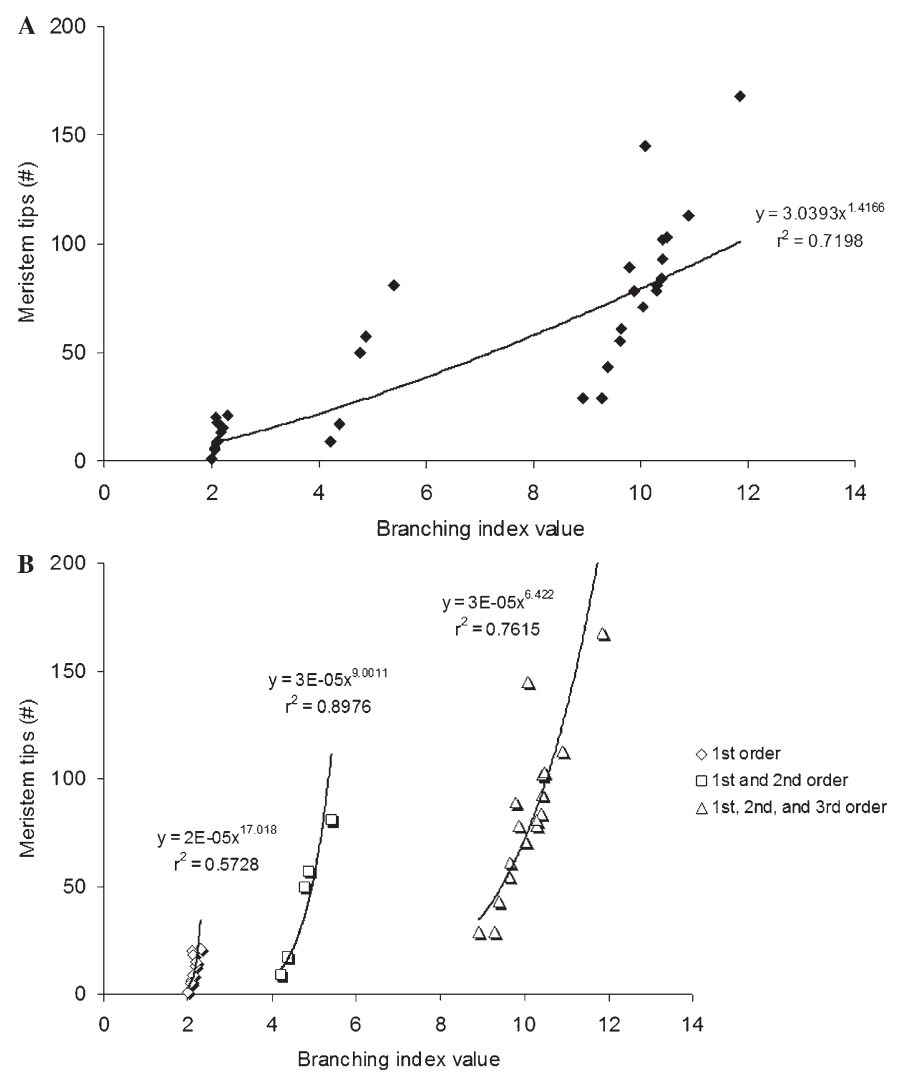

Fig. 4. Branching index values generated for 2007 plotted against the number of meristem tips in FL97-47C peach $\times$ 'Tardy Nonpareil' $(\mathrm{TNP})$ almond, 'Okinawa' (Oki) peach $\times P$. kansuensis 'A' (Pkan), 'Flordaguard' $(\mathrm{FG})$ peach $\times$ P. kansuensis 'A', and 'Flordaguard' peach $\times$ 'Tardy Nonpareil' almond progeny. (A) The regression line generated for the entire 2007 data set. (B) The regression lines generated for the first-, second-, and third-order clusters formed by the index. Index values were calculated using the total number of first-order branches per tree and the mean of three randomly selected first-order branches in the case of second- and third-order branches. 

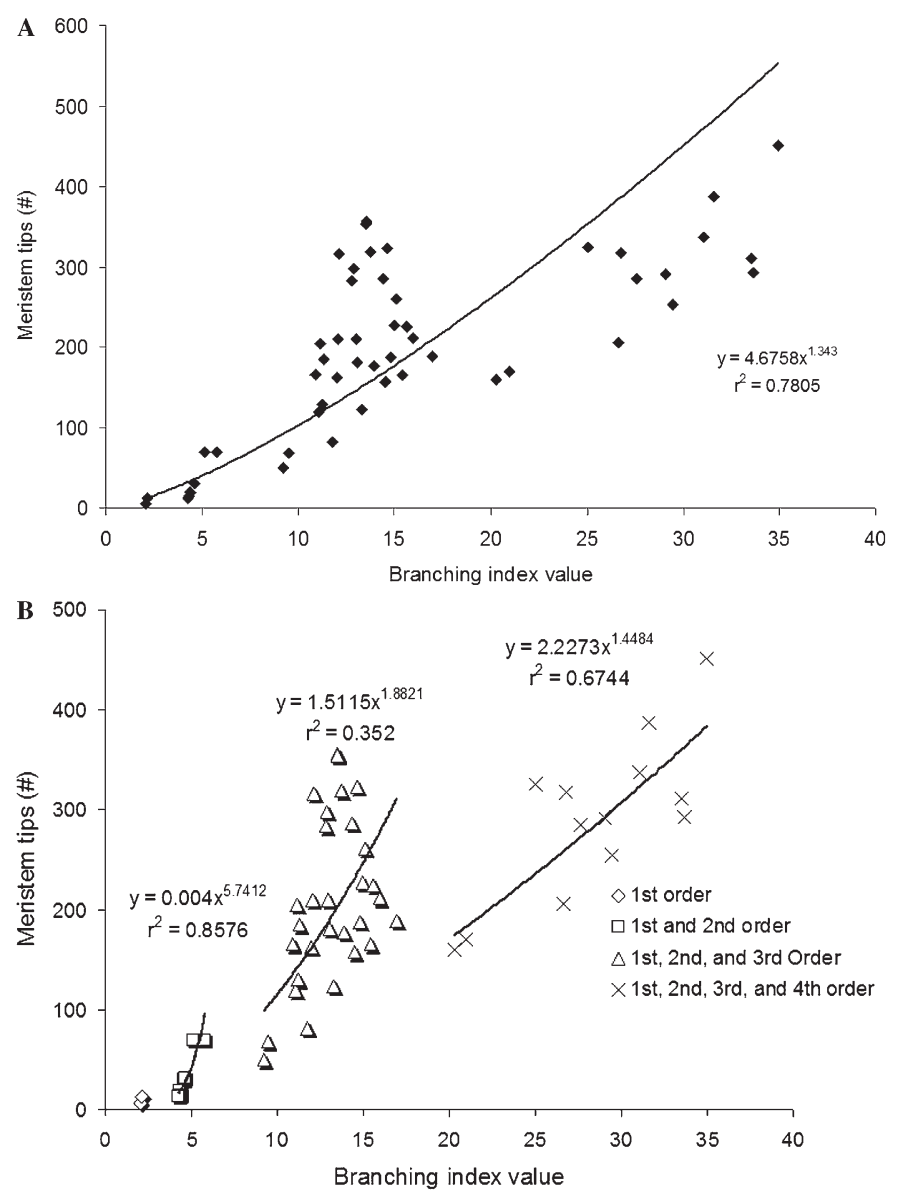

Fig. 5. Branching index values generated for 2008 plotted against the number of meristem tips in FL97-47C peach $\times$ 'Tardy Nonpareil' (TNP) almond, 'Okinawa' (Oki) peach $\times$ P. kansuensis 'A' (Pkan), 'Flordaguard' (FG) peach $\times$ P. kansuensis ' $\mathrm{A}$ ', and 'Flordaguard' peach $\times$ 'Tardy Nonpareil' almond progeny. (A) The regression line generated for the entire 2008 data set. (B) The regression lines generated for the second-, third-, and fourth-order clusters formed by the index. Index values were calculated using the total number of first-order branches per tree and the mean of three randomly selected first-order branches in the case of second-, third-, and fourth-order branches.

5B). Index values increased from 2007 to 2008 as the trees increased in size and complexity (Figs. 4A and 5A). Furthermore, BI values became more dispersed as branch number and branching complexity increased resulting in a decrease in the goodness of fit of the 2008 regression lines (Fig. 5). However, the lowest

index values within each branching cluster identified the plants with the fewest number of branches. The regression of the $2007 \mathrm{BI}$ values and the total number of branches observed in 2008 was 0.71 (Fig. 6), indicating that the index values generated in 2007 were good predictors of branching in 2008

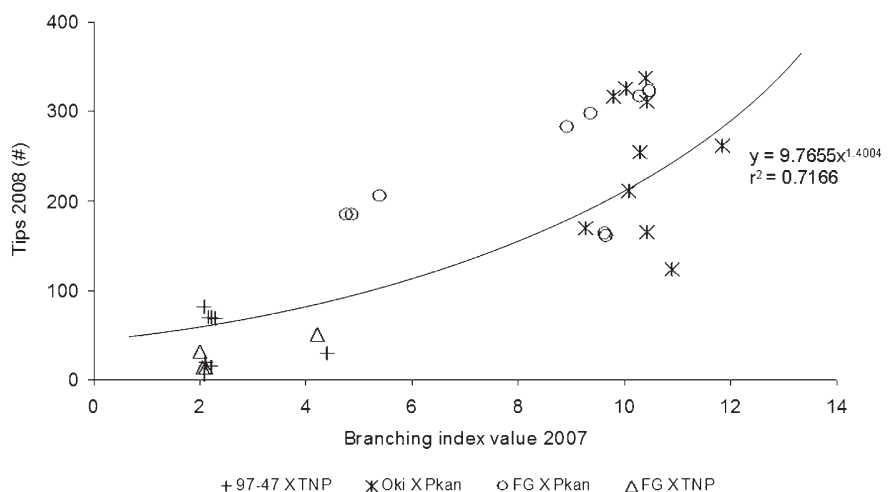

Fig. 6. Branching index values calculated in 2007 as a predictor for branching frequency in 2008 using FL97-47C peach $\times$ 'Tardy Nonpareil' (TNP) almond, 'Okinawa' (Oki) peach $\times$ P. kansuensis (Pkan), 'Flordaguard' $(\mathrm{FG})$ peach $\times P$. kansuensis, and 'Flordaguard' peach $\times$ 'Tardy Nonpareil' almond progeny. Index value was calculated using the mean of three randomly selected first-order branches per tree in the case of second- and third-order branches.

Counting the number of first-order, secondorder, and third-order branches on each seedling requires a significant time investment. Therefore, we compared the linear regressions generated by using data from each of the firstorder branches sampled versus the mean of three sampled branches in 2008. The results indicate that the three-branch data (Fig. 5A) generate index values that are better estimators of tree branching than individual branch data for a basal, intermediate, and upper branch (Figs. 7A, 7B, and 7C, respectively). Among individual branches, those in the basal and upper third of the canopy (Figs. 7A and 7C) give more accurate indices $\left(r^{2}=0.62\right.$ and 0.65$)$ than those in the intermediate third of the canopy $\left(r^{2}=0.52\right)$ (Fig. 7B). The upper branch gives the highest regression value and the best separation of the branching clusters of the individual branches (Fig. 7C).

In conclusion, the developed index revealed differences in branching patterns among interspecific hybrids over two growing seasons and the index values calculated in two-year-old trees were good predictors of the branching observed in the third year. Furthermore, the index was more precise when three first-order branches were sampled per tree rather than one. The results indicate that selection of trees with an index value below 8 at 2 years and below 12 at 3 years of age would select trees with reduced branching. Operationally, the index would be based on the mean from three first-order branches and used to select trees within the branching clusters generated by the index. The lowest index values within each branching cluster typically have the fewest branches.

This index could be used in peach breeding as a quantitative way of selecting individuals with decreased branching and less twiggy tree architecture. Further research is necessary to evaluate the ability of this index to predict branching in larger trees. However, the close tree spacing used in this experiment will prevent the further analysis of this population as a result of shading and competition between trees.

\section{Literature Cited}

Berthelemy, D. and Y. Caraglio. 2007. Plant architecture: A dynamic, multilevel and comprehensive approach to plant form, structure and ontogeny. Ann. Bot. (Lond.) 99:375-407.

Birch, C. and M.J. Hutchings. 1992. Stolon growth and branching in Glechoma hederacea L.: An application of a plastochron index. New Phytol. 122:545-551.

Fourcaud, T., X. Zhang, A. Stokes, H. Lambers, and C.K. Örner. 2008. Plant growth modeling and applications: The increasing importance of plant architecture in growth models. Ann. Bot. (Lond.) 101:1053-1063.

Genard, M., L. Pages, and J. Kervella. 1994. Relationship between sylleptic branching and components of parent shoot developments in the peach tree. Ann. Bot. (Lond.) 74:465-470.

Godin, C., E. Costes, and H. Sinoquet. 1999. A method for describing plant architecture which integrates topology and geometry. Ann. Bot. (Lond.) 84:343-357. 

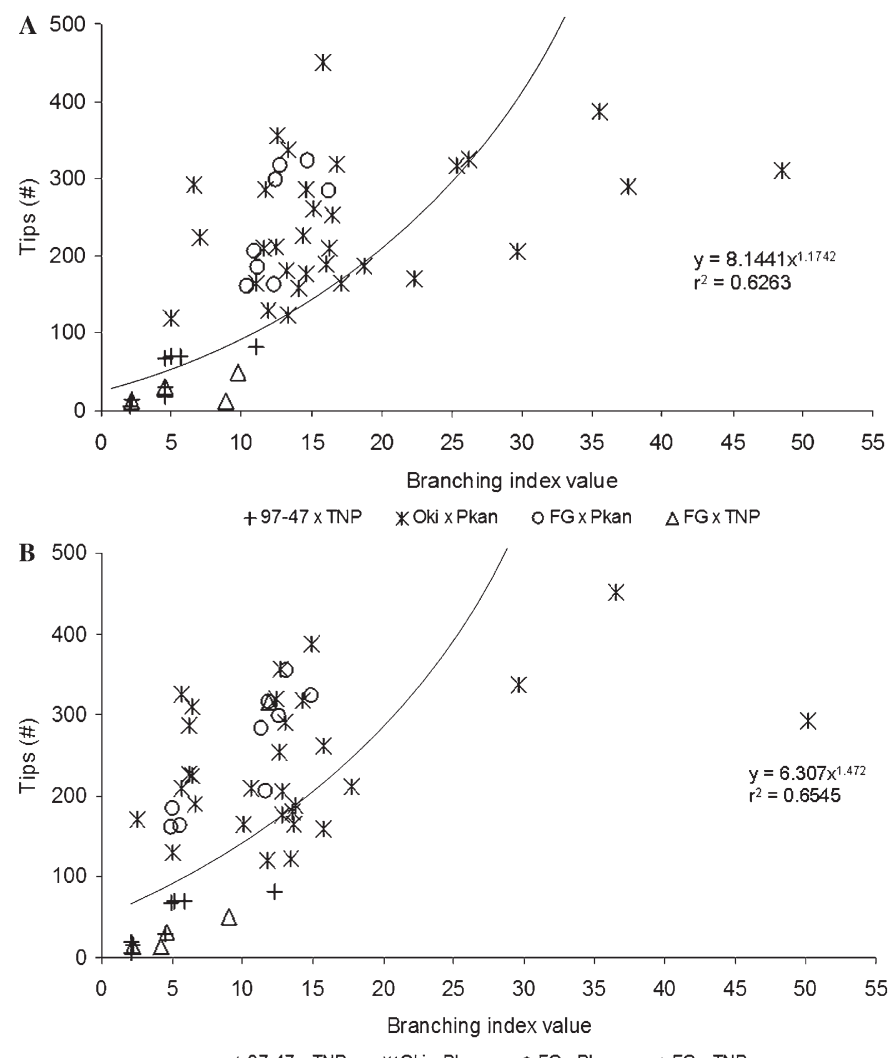

Gradziel, T.M., D.E. Kester, and P. MartinezGomez. 2002. A development based classification for branch architecture in almond. J. Amer Pom. Soc. 56:106-122.

Laurens, F., J.M. Audergon, J. Claviere, J. Duval, H. Germain, J. Kervella, M. Le Lezec, P.E. Lauri, and J.M. Lespinasse. 2000. Integration of architectural types in French programmes of ligneous fruits species genetic improvement. Fruits 55:141-152.

Legave, J.M., V. Segura, D. Fournier, and E. Costes. 2006. The effect of genotype, location and their interaction on early growth and branching in apricot trees. J. Hort. Sci. Biotechnol. 81:189-198.

Morita, S., S. Thongpae, J. Abe, T. Nakamoto, and K. Yamazaki. 1992. Root branching in maize. Branching index and methods for measuring root length. Jpn. J. Crop. Sci. 61:101-106.

Segura, V., C. Cilas, F. Laurens, and E. Costes. 2006. Phenotyping progenies for complex architectural traits: A strategy for 1-year-old apple trees (Malus $\times$ domestica Borkh.). Tree Genet. Genomes 2:140-151.

Sherman, W.B., P.M. Lyrene, and R.H. Sharpe 1991. Flordaguard peach rootstock. HortScience 26:427-428.

Tworkoski, T. and R. Scorza. 2001. Root and shoot characteristics of peach trees with different growth habits. J. Amer. Soc. Hort. Sci. 126: 785-790.

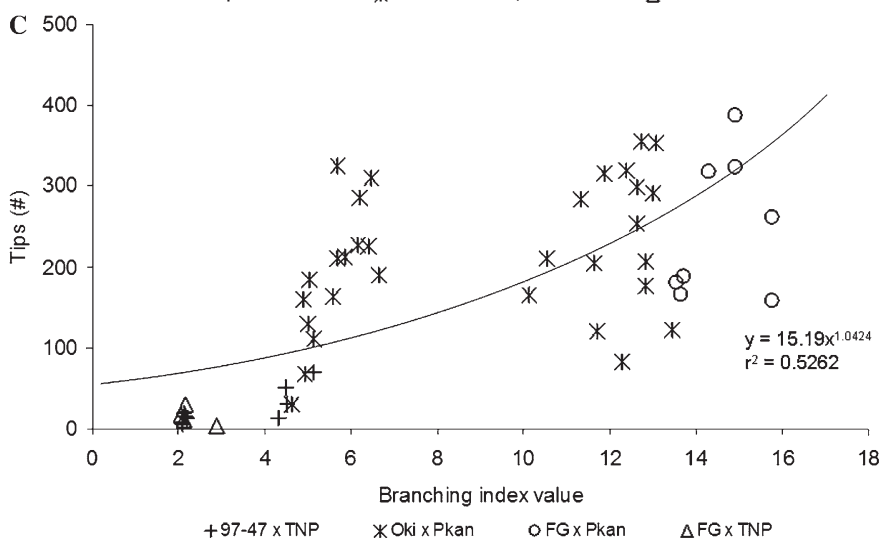

Fig. 7. Branching index values calculated in 2008 plotted against number of meristem tips per tree in a seedling population. Index value was calculated using total number of first-order branches per tree and the number of second-, third-, and fourth-order branches within a randomly selected first-order branch in the basal (A), intermediate (B), and upper (C) third of the canopy. 